\title{
Author Spotlight: Costantino Sgamato
}

\section{Costantino Sgamato ${ }^{1}$}

Accepted: 7 October 2020 / Published online: 29 October 2020

(c) Springer Science+Business Media, LLC, part of Springer Nature 2020

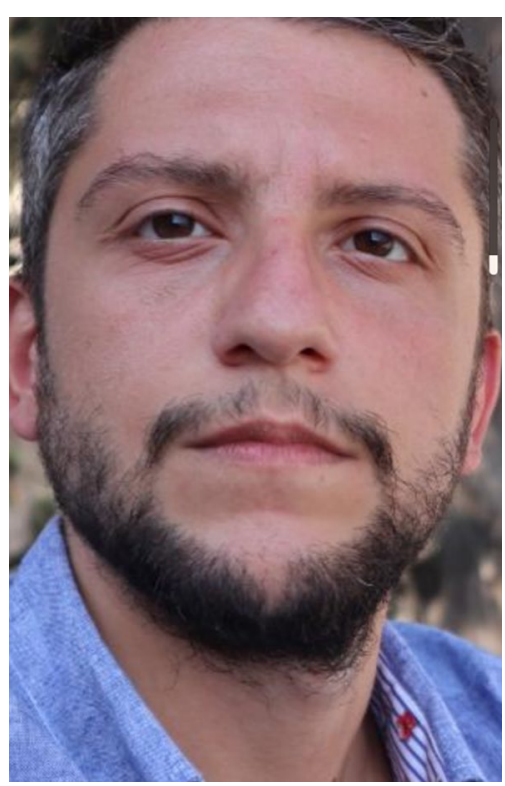

Dr. Costantino Sgamato, MD, graduated in gastroenterology at the University Federico II of Naples in December 2019.
His clinical and research interests include chronic liver diseases and hepatocellular carcinoma diagnosis and treatment.

Publisher's Note Springer Nature remains neutral with regard to jurisdictional claims in published maps and institutional affiliations.

Costantino Sgamato

costa.sgamato@gmail.com

1 University Federico II of Naples, Naples, Italy 